\title{
Neutrophil to Lymphocyte Ratio in Acute Ischemic Stroke
}

\author{
Menat-Allah Mohamed Lashin1, Salma Hamed Khalil1, Taha Kamel Alloush1, Sherif Anis2, \\ Mohamed Mahmoud Fouad1
}

\author{
${ }^{1}$ Department of Neurology, Faculty of Medicine, Ain Shams University, Cairo, Egypt \\ ${ }^{2}$ Department of Anesthesia, Faculty of Medicine, Ain Shams University, Cairo, Egypt \\ Email: drfoash@hotmail.com
}

How to cite this paper: Lashin, M.-A.M., Khalil, S.H., Alloush, T.K., Anis, S. and Fouad, M.M. (2020) Neutrophil to Lymphocyte Ratio in Acute Ischemic Stroke. Neuroscience \& Medicine, 11, 52-62. https://doi.org/10.4236/nm.2020.112007

Received: April 2, 2020

Accepted: June 1, 2020

Published: June 4, 2020

Copyright (c) 2020 by author(s) and Scientific Research Publishing Inc. This work is licensed under the Creative Commons Attribution International License (CC BY 4.0).

http://creativecommons.org/licenses/by/4.0/

(c) (i) Open Access

\begin{abstract}
Introduction: The neutrophil to lymphocyte ratio (NLR) can be used as a marker of subclinical inflammation, and may have a predictive power in prognosis and severity of atherosclerosis-related diseases. This study aimed to assess an association between the NLR, and clinical characteristics and onemonth outcome in acute ischemic stroke (AIS). Subjects and Methods: This case-control observational prospective study included 75 patients admitted to stroke unit of Ain Shams University hospitals with AIS, sub grouped into 3 equal groups according to subtype of AIS, in addition to 25 healthy individuals. The demographic characteristics of the patients, complete blood picture test results at presentation, National Institutes of Health Stroke Scale (NIHSS) scores and modified Rankin Scale (mRS) scores were recorded. The clinical outcome was assessed by the NIHSS and mRS scores after one month. Results: The total leucocyte count was significantly higher in large artery atherosclerosis $(\mathrm{P}=0.004)$ and cardioembolic $(\mathrm{P}=0.020)$ stroke groups, unlike lacunar stroke group $(\mathrm{P}=0.082)$, when compared to controls. The neutrophils count was higher $(\mathrm{P}<0.001)$ and the lymphocyte count was lower $(\mathrm{P}<$ 0.001) among all the stroke groups compared to the control group. The NLR was higher among all the stroke groups compared to the control group $(\mathrm{P}<$ $0.001)$. The NLR at cutoff value more than 1.34 had predicted stroke with a sensitivity of $89.33 \%$ and specificity of $72 \%$ and accuracy reached $88.6 \%$. There was non-significant association between NLR and each of NIHSS and mRS after one month from onset of AIS. Conclusion: NLR was significantly higher among AIS subtypes compared to controls, but not a good predictor for one month outcome.
\end{abstract}

\section{Keywords}

Neutrophil to Lymphocyte Ratio, Acute Ischemic Stroke 


\section{Introduction}

In medicine neutrophil to lymphocyte ratio (NLR) is used as a marker of subclinical inflammation that can be easily obtained from the differential white blood cell count [1]. Clinical studies suggested that higher leucocyte and subtype counts as well as higher NLR levels might have a predictive power in prognosis and severity of atherosclerosis and cardiovascular diseases [2]. This study was performed to assess a correlation between NLR and subtypes of acute ischemic stroke (AIS) and one-month outcome.

\section{Subjects and Methods}

This study enrolled 75 patients with the diagnosis of first ever AIS as a case group and 25 healthy age-matched and sex-matched individuals as a control group. The patients were presenting to the emergency room of Ain Shams University hospitals during the period from November 2017 to June 2018, and were admitted to the stroke unit of neurology department within 24 hours from onset of symptoms. Patients were diagnosed as AIS based on neurological history, clinical examination and radiological investigations. The patients (from both genders) were recruited consecutively after their agreement to participate in the study and obtaining the informed consent from themselves or a first degree relative if unable to write or understand. The patients were divided into 3 equal groups (each one including 25 patients): large artery atherosclerosis, cardioembolic and lacunar stroke groups defined according to the TOAST criteria based on risk factors as well as clinical and brain imaging features [3].

Patients with a comorbid or diagnosis of chronic inflammatory and infectious diseases, patients with active systemic bacterial, viral, fungal infections or diagnosis of Hepatitis B and Hepatitis C (either by history or discovered after investigations), patients with previous cerebrovascular stroke, patients below 18 years, patients who had received corticosteroids within 30 days from the time of sample withdrawal, and patients who had received immunosuppressive medications within 6 months prior to the time of sample withdrawal were excluded from this study.

The study team did not interfere with the treatments that the recruited patient had received. As per the protocol of stroke unit of Ain Shams University, all candidate patients presenting to the emergency room within 6 hours from onset of symptoms should be planned to receive any of the reperfusion therapies (intravenous alteplase or mechanical thrombectomy) unless contraindicated.

Review of the medical history for age, gender, smoking, and vascular risk factors such as hypertension, diabetes mellitus, and cardiac diseases was done. All of the patients were subjected to detailed neurological examination with assessment of stroke severity using the National Institute of Health Stroke Scale (NIHSS) score done on admission, after 24 hours from admission, and at one month from onset of symptoms. According to NIHSS score, patient was defined to have no disability if the score was zero, mild disability if the score ranged from 1 to 4 , moderate disability if the score ranged from 5 to 15 , severe disability 
if the score 16 or more.

The patients' functional status was assessed using the modified Rankin scale (mRS) done on admission and at one-month follow up. The one-month outcome was defined as no disability if $\mathrm{mRS}$ score was zero, favorable if mRS score was 1 or 2 (a patient can perform the daily activities independently) or unfavorable if mRS score ranged from 3 to 6 (a dependent patient or dead).

The laboratory investigations included complete blood count (CBC) with differential leucocyte count at the time of admission. Magnetic resonance imaging (MRI) of the brain was done, using a 1.5 Tesla MR system (Achieva, Philips), for all of the patients including DWI, FLAIR, T1WI, T2WI and gradient-echo T2* weighted MRI scans. Magnetic resonance angiography (MRA) will be visualized for the presence of intracranial arterial stenosis or occlusion. B-mode and color coded duplex sonography of the extracranial vessels of the common carotid arteries and internal carotid arteries was done for assessment of extracranial stenosis or occlusion. An Electrocardiogram (ECG), transthoracic and transesophageal echocardiography were done for all of the patients. Blood samples were collected from all the participants after obtaining an informed consent and the neutrophil and lymphocyte counts had been collected from the CBC, and then the NLR values had been calculated.

\section{Statistical Methods}

The collected data were coded, tabulated, and statistically analyzed using IBM SPSS statistics (Statistical Package for Social Sciences) software version 22.0, IBM Corp., Chicago, USA, 2013.

Descriptive statistics were done for quantitative data as minimum and maximum of the range as well as mean $\pm \mathrm{SD}$ (standard deviation) for quantitative normally distributed data, number and percentage was done for qualitative data. Inferential analyses were done for quantitative variables using ANOVA test with post hoc Tukey test for more than two independent groups with normally distributed data and Kruskal Wallis test with post hoc Dunn's test for more than two independent groups with non-normally distributed data. In qualitative data, inferential analyses for independent variables were done using Chi square test for differences between proportions and Fisher's Exact test for variables with small expected numbers with post hoc Bonferroni test. Paired test was used for comparison of quantitative variables among two dependent groups. While correlations were done using spearman rho test for qualitative data. The level of significance was taken at $\mathrm{P}$ value $<0.050$ is significant, otherwise is non-significant.

Receiver Operating Characteristic (ROC) curve analysis was used where sensitivity is the probability that the test results will be positive when the disease is present (true positive rate, expressed as a percentage), specificity is the probability that the test results will be negative when the disease is absent (true negative rate, expressed as a percentage), positive predictive value (PPV) is the probability that the disease is present when the test is positive, negative predictive value (NPV) is the probability that the disease is present when the test is negative and 
the accuracy is the ratio of the true positive and true negative on all patients.

\section{Results}

The demographic data and vascular risk factors of the patients groups are illustrated in Table 1.

There was no statistical significant difference between the 3 patients groups regarding NIHSS scores on admission $(\mathrm{P}=0.097)$, after 24 hours $(\mathrm{P}=0.195)$ and after one month $(\mathrm{P}=0.097)$ (Table 2). Comparing the NIHSS scores on admission to that after 24 hours showed that there was no significant improvement in the lacunar stroke group $(\mathrm{P}=0.083)$, as well as the large artery atherosclerosis stroke group $(P=0.203)$ and cardioembolic stroke group $(P=0.174)$. While comparing NIHSS scores on admission to that after one month showed that there was significant improvement in all of the groups $(\mathrm{P}<0.001)$.

There was no statistical significant difference between the 3 groups regarding mRS scores on admission $(\mathrm{P}=0.373)$ and after month $(\mathrm{P}=0.355)$ (Table 3$)$. The comparison between $\mathrm{mRS}$ on admission and after month showed significant improvement in all of the three groups $(\mathrm{P}<0.001)$.

The analysis of results of $\mathrm{CBC}$ showed the AIS patients had higher total leucocyte count (TLC) compared to the controls $(\mathrm{P}=0.004)$. TLC was significantly higher in the large artery atherosclerosis and cardioembolic stroke groups compared to the controls $(\mathrm{P}=0.004$ and $\mathrm{P}=0.020$ respectively). There was non-significant difference when comparing patients with lacunar stroke to controls $(\mathrm{P}=$ 0.082) (Table 4).

The AIS patients had significantly higher neutrophils count compared to the controls $(\mathrm{P}<0.001)$. Patients in large artery atherosclerosis, cardioembolic and lacunar stroke groups had significantly higher neutrophils count when compared to the controls $(\mathrm{P}<0.001, \mathrm{P}<0.001$ and $\mathrm{P}=0.002$ respectively) (Table 5).

Table 1. Demographics and vascular risk factors among the patients groups.

\begin{tabular}{|c|c|c|c|c|c|c|}
\hline & & \multicolumn{3}{|c|}{ Stroke groups } & \multicolumn{2}{|c|}{ Chi-Square } \\
\hline & & $\begin{array}{c}\text { Large artery } \\
\text { atherosclerosis }(n=25)\end{array}$ & $\begin{array}{c}\text { Cardioembolic } \\
\quad(n=25)\end{array}$ & Lacunar $(n=25)$ & $\mathrm{X}^{2}$ & P-value \\
\hline \multirow{2}{*}{ Gender } & Male & $17(68.0 \%)$ & $14(56.0 \%)$ & $16(64.0 \%)$ & \multirow{2}{*}{1.135} & \multirow{2}{*}{0.769} \\
\hline & Female & $8(32.0 \%)$ & $11(44.0 \%)$ & $9(36.0 \%)$ & & \\
\hline \multirow[b]{2}{*}{ Age (years) } & Range & $46-85$ & $24-87$ & $34-78$ & \multirow[b]{2}{*}{4.677} & \multirow[b]{2}{*}{0.817} \\
\hline & Mean \pm SD & $64.48 \pm 10.62$ & $65.44 \pm 12.54$ & $63.20 \pm 10.63$ & & \\
\hline \multirow{2}{*}{ Hypertension } & Positive & $21(84.0 \%)$ & $19(76.0 \%)$ & $19(76.0 \%)$ & \multirow{2}{*}{0.636} & \multirow{2}{*}{0.728} \\
\hline & Negative & $4(16.0 \%)$ & $6(24.0 \%)$ & $6(24.0 \%)$ & & \\
\hline \multirow[b]{2}{*}{ Diabetes mellitus } & Positive & $13(52.0 \%)$ & $9(36.0 \%)$ & $16(64.0 \%)$ & \multirow[b]{2}{*}{3.947} & \multirow[b]{2}{*}{0.139} \\
\hline & Negative & $12(48.0 \%)$ & $16(64.0 \%)$ & $9(36.0 \%)$ & & \\
\hline \multirow{2}{*}{$\begin{array}{l}\text { Presence of cardiac diseases } \\
\text { as atrial fibrillation, ischemic } \\
\text { or valvular heart disease }\end{array}$} & Positive & $9(36.0 \%)$ & $25(100.0 \%)$ & $8(32.0 \%)$ & \multirow[b]{2}{*}{29.545} & \multirow[b]{2}{*}{$<0.001$} \\
\hline & Negative & $16(64.0 \%)$ & $0(0.0 \%)$ & $17(68.0 \%)$ & & \\
\hline
\end{tabular}


Table 2. Comparison between groups regarding NIHSS on admission, after 24 hours and after one month.

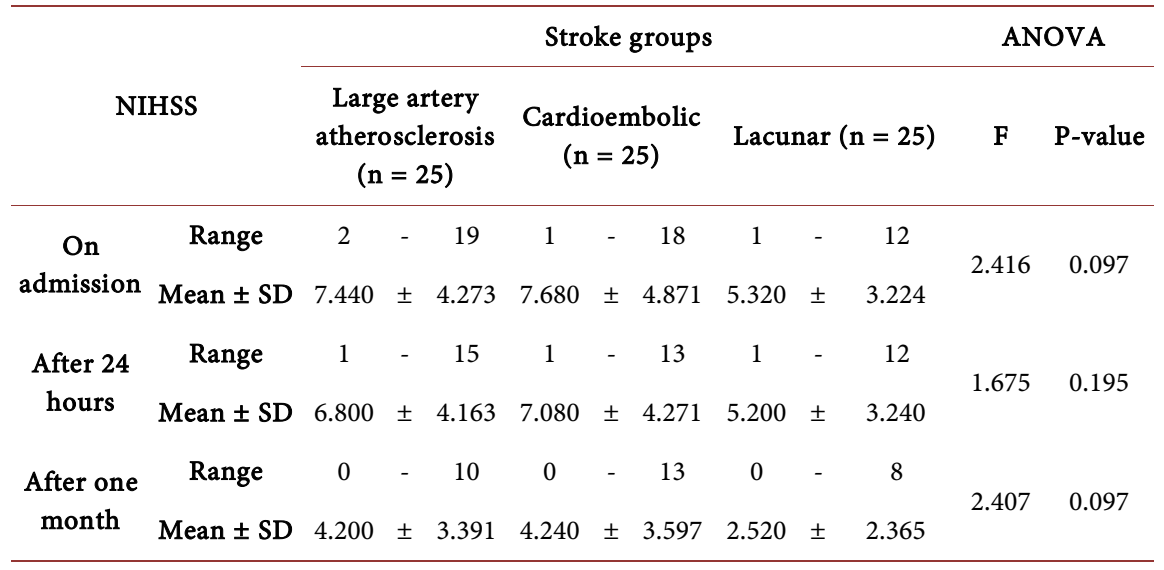

Table 3. Comparison between stroke groups regarding mRS scores on admission and after one month.

\begin{tabular}{|c|c|c|c|c|c|c|c|c|c|c|c|c|}
\hline & & \multicolumn{9}{|c|}{ Stroke groups } & \multicolumn{2}{|c|}{ ANOVA } \\
\hline \multicolumn{2}{|c|}{ mRS score } & \multicolumn{3}{|c|}{$\begin{array}{c}\text { Large artery } \\
\text { Atherosclerosis }(n=25)\end{array}$} & \multicolumn{3}{|c|}{ Cardioembolic $(n=25)$} & \multicolumn{3}{|c|}{ Lacunar $(n=25)$} & \multirow[t]{2}{*}{$\mathbf{F}$} & \multirow[t]{2}{*}{ P-value } \\
\hline \multirow[b]{2}{*}{ On admission } & Range & 1 & - & 5 & 1 & - & 5 & 1 & - & 5 & & \\
\hline & Mean \pm SD & 3.360 & \pm & 1.350 & 3.360 & \pm & 1.440 & 2.880 & \pm & 1.364 & 1.001 & 0.373 \\
\hline \multirow{2}{*}{ After one month } & Range & 0 & - & 6 & 0 & - & 6 & 0 & - & 6 & \multirow{2}{*}{1.050} & \multirow{2}{*}{0.355} \\
\hline & Mean \pm SD & 2.200 & \pm & 1.607 & 2.480 & \pm & 1.711 & 1.800 & \pm & 1.683 & & \\
\hline
\end{tabular}

Table 4. Comparison between groups regarding TLC.

\begin{tabular}{|c|c|c|c|c|c|c|c|c|}
\hline \multirow{2}{*}{\multicolumn{2}{|c|}{ Study groups }} & \multicolumn{5}{|c|}{$\operatorname{TLC}\left(10^{3} / \mathrm{uL}\right)$} & \multicolumn{2}{|c|}{ ANOVA } \\
\hline & & \multicolumn{2}{|c|}{ Range } & \multirow{2}{*}{$\begin{array}{l}\text { Mean } \\
8.524\end{array}$} & \multirow{2}{*}{$\begin{array}{l} \pm \\
\pm\end{array}$} & \multirow{2}{*}{$\begin{array}{c}\text { SD } \\
1.643\end{array}$} & \multirow[t]{2}{*}{ F } & \multirow[t]{2}{*}{ P-value } \\
\hline $\begin{array}{r}\text { Large ar } \\
\text { (I }\end{array}$ & $\begin{array}{l}\text { AA) }(n=25)\end{array}$ & 5.3 & - 12.6 & & & & & \\
\hline Cardioer & bolic $(C E)(n=25)$ & 4.2 & - 11.7 & 8.240 & \pm & 2.170 & 4.734 & 0.004 \\
\hline $\mathrm{La}$ & unar $(n=25)$ & 4.1 & -12.1 & 7.944 & \pm & 2.146 & & \\
\hline $\mathrm{Co}$ & ntrol $(n=25)$ & 4.5 & $\begin{array}{ll}- & 10.7\end{array}$ & 6.637 & \pm & 1.636 & & \\
\hline \multicolumn{9}{|c|}{ TUKEY'S Test } \\
\hline \multicolumn{2}{|c|}{ LAA vs CE LAA vs Lacunar L } & \multicolumn{3}{|c|}{ vs Control CE vs Lacunar } & \multicolumn{2}{|c|}{$\begin{array}{c}\text { CE vs } \\
\text { Control }\end{array}$} & \multicolumn{2}{|c|}{$\begin{array}{c}\text { Lacunar vs } \\
\text { Control }\end{array}$} \\
\hline 0.953 & 0.709 & 0.004 & & 0.947 & & 0.020 & & 082 \\
\hline
\end{tabular}

The AIS patients had significantly lower lymphocytes count compared to the controls $(\mathrm{P}<0.001)$. Patients in large artery atherosclerosis, cardioembolic and lacunar stroke groups had significantly lower lymphocytes count when compared to the controls $(\mathrm{P}=0.001, \mathrm{P}=0.001$ and $\mathrm{P}=0.010$ respectively) (Table 6).

There was a significant difference between case and control groups as regards NLR being higher among all the stroke groups compared to the control group ( $\mathrm{P}$ 
Table 5. Comparison between groups regarding neutrophils count.

\begin{tabular}{|c|c|c|c|c|c|c|c|c|}
\hline \multirow{2}{*}{\multicolumn{2}{|c|}{ Study groups }} & \multicolumn{5}{|c|}{ Neutrophils $\left(10^{3} / \mathrm{uL}\right)$} & \multicolumn{2}{|c|}{ ANOVA } \\
\hline & & \multicolumn{2}{|c|}{ Range } & \multirow{2}{*}{$\begin{array}{l}\text { Mean } \\
5.749\end{array}$} & \multirow{2}{*}{$\begin{array}{l} \pm \\
\pm\end{array}$} & \multirow{2}{*}{$\begin{array}{c}\text { SD } \\
1.526\end{array}$} & \multirow[t]{2}{*}{$\mathrm{F}$} & \multirow[t]{2}{*}{$P$-value } \\
\hline $\begin{array}{r}\text { Large ar } \\
(\mathrm{L}\end{array}$ & $\begin{array}{l}\text { ery atherosclerosis } \\
\text { AA) }(n=25)\end{array}$ & 2.8 & -9.3 & & & & & \\
\hline Cardioen & bolic (CE) $(n=25)$ & 2.1 & -9.2 & 5.552 & \pm & 1.931 & 10.254 & $<0.001$ \\
\hline $\mathrm{Lac}$ & $\operatorname{unar}(n=25)$ & 1.7 & -8.8 & 5.150 & \pm & 2.073 & & \\
\hline Co & trol $(n=25)$ & 1.3 & -5.4 & 3.302 & \pm & 1.360 & & \\
\hline \multicolumn{9}{|c|}{ TUKEY'S Test } \\
\hline LAA vs CE & \multicolumn{4}{|c|}{ LAA vs Lacunar LAA vs Control CE vs Lacunar } & & $\begin{array}{l}\text { CE vs } \\
\text { Oontrol }\end{array}$ & \multicolumn{2}{|c|}{$\begin{array}{l}\text { Lacunar vs } \\
\text { Control }\end{array}$} \\
\hline 0.979 & 0.620 & \multicolumn{2}{|l|}{$<0.001$} & 0.847 & \multicolumn{2}{|c|}{$<0.001$} & \multicolumn{2}{|c|}{0.002} \\
\hline
\end{tabular}

Table 6. Comparison between groups regarding lymphocytes count.

\begin{tabular}{|c|c|c|c|c|c|c|c|c|c|}
\hline \multirow{2}{*}{\multicolumn{2}{|c|}{ Study groups }} & \multicolumn{6}{|c|}{ Lymphocytes $\left(10^{3} / \mathrm{uL}\right)$} & \multicolumn{2}{|c|}{ ANOVA } \\
\hline & & \multicolumn{3}{|c|}{ Range } & \multirow{2}{*}{$\begin{array}{l}\text { Mean } \\
1.940\end{array}$} & \multirow{2}{*}{$\begin{array}{l} \pm \\
\pm\end{array}$} & \multirow{2}{*}{$\begin{array}{c}\text { SD } \\
0.823\end{array}$} & \multirow[t]{2}{*}{$\mathbf{F}$} & \multirow[t]{2}{*}{ P-value } \\
\hline $\begin{array}{r}\text { Large ar } \\
(\mathrm{L}\end{array}$ & $\begin{array}{l}\text { tery atherosclerosis } \\
\text { AA) }(n=25)\end{array}$ & 0.7 & - & 4.0 & & & & & \\
\hline Cardioen & abolic $(C E)(n=25)$ & 0.8 & - & 3.1 & 1.933 & \pm & 0.544 & 7.464 & $<0.001$ \\
\hline $\mathrm{Lac}$ & cunar $(n=25)$ & 1.0 & - & 4.1 & 2.114 & \pm & 0.852 & & \\
\hline Co & ntrol $(n=25)$ & 1.6 & - & 4.8 & 2.779 & \pm & 0.671 & & \\
\hline \multicolumn{10}{|c|}{ TUKEY'S Test } \\
\hline \multicolumn{2}{|c|}{ LAA vs CE LAA vs Lacuna } & \multicolumn{4}{|c|}{ vs Control CE vs Lacunar } & \multicolumn{2}{|c|}{$\begin{array}{c}\text { CE vs } \\
\text { Control }\end{array}$} & \multicolumn{2}{|c|}{$\begin{array}{l}\text { Lacunar vs } \\
\text { Control }\end{array}$} \\
\hline 1.000 & 0.835 & 0.001 & & & 0.818 & & 0.001 & & 10 \\
\hline
\end{tabular}

$<0.001)$. The NLR was significantly higher in large artery atherosclerosis, cardioembolic, and lacunar stroke groups compared to control group $(\mathrm{P}<0.001, \mathrm{P}$ $=0.001$ and $\mathrm{P}=0.002$ respectively). There were non-significant differences when comparing the stroke groups to each other (Table 7).

The comparison between all of the stroke cases and controls as regards NLR using Roc curve analysis (Figure 1) showed that a cutoff value more than 1.34 had predicted stroke with a sensitivity of $89.33 \%$ and specificity of $72 \%$ and accuracy reached $88.6 \%$. The positive predictive value of NLR in stroke cases was $90.5 \%$ and the negative predictive value was $69.2 \%$ (Figure 1 ).

At the follow up visit after one month from onset of stroke, when the patients were classified according to their NIHSS scores, there was no statistical significant difference as regards the NLR $(\mathrm{P}=0.189)$. Also there was no statistical significant difference between functional outcome classified according to mRS scores and the NLR $(\mathrm{P}=0.598)$ (Table 8).

There were no significant correlations between age $(r=0.018, P=0.879)$, NIHSS score on admission $(r=0.054, P=0.648)$, NIHSS score after one month 
Table 7. Comparison between groups regarding NLR.

\begin{tabular}{|c|c|c|c|c|c|c|c|c|}
\hline \multirow{2}{*}{\multicolumn{2}{|c|}{ Study groups }} & \multicolumn{5}{|c|}{ Neutrophil lymphocyte ratio } & \multicolumn{2}{|c|}{ ANOVA } \\
\hline & & \multicolumn{2}{|c|}{ Range } & \multirow{2}{*}{$\begin{array}{l}\text { Mean } \\
3.609\end{array}$} & \multirow{2}{*}{$\begin{array}{l} \pm \\
\pm\end{array}$} & \multirow{2}{*}{$\begin{array}{c}\text { SD } \\
2.012\end{array}$} & \multirow[t]{2}{*}{ F } & \multirow[t]{2}{*}{ P-value } \\
\hline $\begin{array}{r}\text { Large ar } \\
\text { (L }\end{array}$ & $\begin{array}{l}\text { tery atherosclerosis } \\
\text { AA) }(n=25)\end{array}$ & 0.83 & - 9.38 & & & & & \\
\hline Cardioen & abolic (CE) $(n=25)$ & 1.29 & -6.71 & 3.078 & \pm & 1.392 & 10.142 & $<0.001$ \\
\hline & unar $(n=25)$ & 0.88 & - 7.55 & 2.922 & \pm & 1.962 & & \\
\hline & ntrol $(\mathrm{n}=25)$ & 0.38 & -2.41 & 1.255 & \pm & 0.610 & & \\
\hline \multicolumn{9}{|c|}{ TUKEY'S Test } \\
\hline \multicolumn{2}{|c|}{ LAA vs CE L } & \multicolumn{3}{|c|}{ vs Control CE vs Lacunar } & \multicolumn{2}{|c|}{$\begin{array}{l}\text { CE vs } \\
\text { Control }\end{array}$} & \multicolumn{2}{|c|}{$\begin{array}{l}\text { Lacunar vs } \\
\text { Control }\end{array}$} \\
\hline 0.644 & 0.430 & $<0.001$ & & 0.986 & & 0.001 & & 002 \\
\hline
\end{tabular}

Table 8. Correlation between NLR and severity of stroke in patients after one month regarding NIHSS and mRS scores.

\begin{tabular}{|c|c|c|c|c|c|c|c|c|c|}
\hline & \multirow{2}{*}{ Variable } & \multicolumn{6}{|c|}{ Neutrophil lymphocytic ratio } & \multicolumn{2}{|c|}{ ANOVA } \\
\hline & & \multicolumn{3}{|c|}{ Range } & Mean & \pm & SD & $\mathbf{F}$ & P-value \\
\hline \multirow{3}{*}{$\begin{array}{l}\text { NIHSS score } \\
\text { after one } \\
\text { month }\end{array}$} & $\begin{array}{c}\text { No disability } \\
(\mathrm{NIHSS}=0)(\mathrm{n}=8)\end{array}$ & 0.92 & - & 6.71 & 2.409 & \pm & 1.943 & & \\
\hline & $\begin{array}{c}\text { Mild disability } \\
(\text { NIHSS } 1-4)(n=40)\end{array}$ & 0.83 & - & 7.55 & 3.067 & \pm & 1.758 & 1.703 & 0.189 \\
\hline & $\begin{array}{c}\text { Moderate disability } \\
(\text { NIHSS } 5-15)(n=27)\end{array}$ & 1.38 & - & 9.38 & 3.640 & \pm & 1.804 & & \\
\hline \multirow{3}{*}{$\begin{array}{l}\text { mRS score } \\
\text { after one } \\
\text { month }\end{array}$} & $\begin{array}{c}\text { No disability } \\
(\mathrm{mRS}=0)(\mathrm{n}=11)\end{array}$ & 0.92 & - & 7.32 & 3.279 & \pm & 2.453 & & \\
\hline & $\begin{array}{c}\text { Favorable } \\
(\mathrm{mRS}=1 \text { or } 2)(n=32)\end{array}$ & 0.83 & - & 9.38 & 2.961 & \pm & 1.935 & 0.518 & 0.598 \\
\hline & $\begin{array}{c}\text { Unfavorable } \\
(m R S=3-6)(n=32)\end{array}$ & 1.42 & - & 7.45 & 3.419 & \pm & 1.423 & & \\
\hline
\end{tabular}

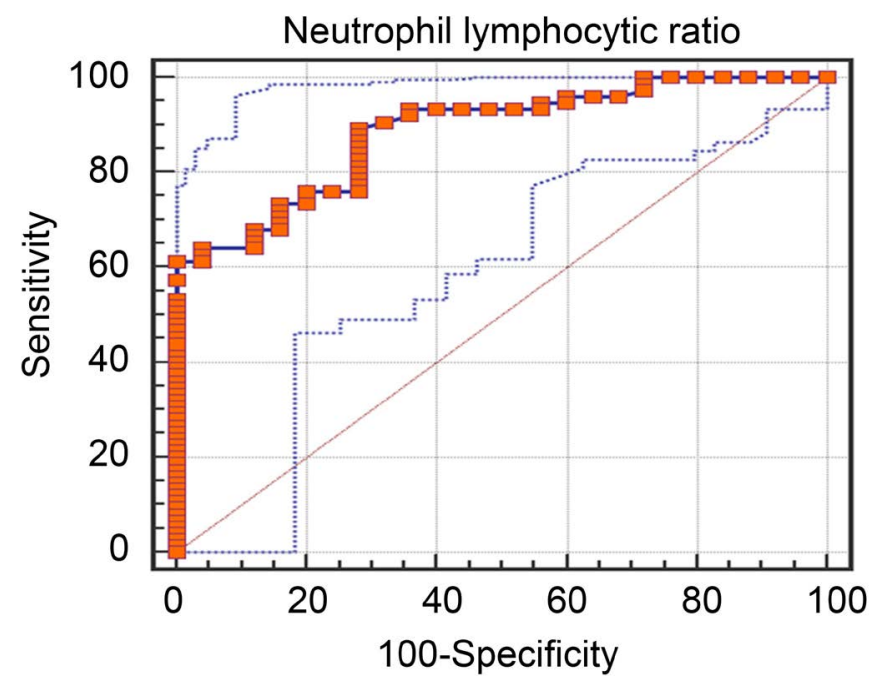

Figure 1. Roc curve between cases and control regarding NLR. 
( $\mathrm{r}=0.168, \mathrm{P}=0.149)$, mRS score on admission $(\mathrm{r}=0.190, \mathrm{P}=0.103), \mathrm{mRS}$ score after one month $(\mathrm{r}=0.155, \mathrm{P}=0.183)$ and NLR (Table 9).

\section{Discussion}

The neutrophil-to-lymphocyte ratio (NLR) is a parameter of inflammation [4] that is easy to obtain and has been proposed as an independent useful prognostic marker to predict the mortality and prognosis of some cardiovascular and neurologic diseases [5]. Many studies have demonstrated that peripheral leucocyte levels increase following cerebrovascular ischemia, and postulated that the initial peripheral leucocyte count following a stroke can help predict stroke severity [6]. It has neen supposed that the leucocyte count at the time of admission is predictive of the likelihood of AIS and the impact of any resulting neurologic disability on daily living activity [5].

In this study, the analysis of the results of CBC showed that patients with large artery atherosclerosis and patients with cardioemolic had significantly higher TLC compared to the controls ( $\mathrm{P}=0.004$ and $\mathrm{P}=0.020$ respectively). Atherosclerosis is considered as an inflammatory disease, and contributes to these 2 subtypes of ischemic strokes, either directly by large-artery atherosclerosis or indirectly by cardioembolic, as a result of cardiac arrhythmias caused by coronary heart disease or emboli after myocardial infarction, that explains why TLC is higher in LAA and cardioembolic stroke groups [7]. Neutrophils have role in initiation and progression of atherosclerosis through a pro-inflammatory activity that can be attributed to the release of preformed granule proteins which localize in the atherosclerotic lesions [8]. Another possible explanation is that usually these stroke subtypes are associated with more disruption of blood brain barrier resulting in the release of pro-inflammatory cytokines which results in increase of blood levels of leucocytes.

This was corroborated in previous study that reported higher TLC in atherosclerotic and cardioembolic stroke subtypes compared to other subtypes [9] [10] [11]. In this study there was non-significant difference between lacunar stroke group and controls as regards TLC $(\mathrm{P}=0.082)$, which may be explained by the fact that lacunar infarction is a small volume infarction and subsequently will result in mild inflammation, and hence lesser increase in TLC. A positive correlation between the volume of infarction and TLC can be hypothesized.

Table 9. Correlations between age, NIHSS scores, mRS scores and NLR.

\begin{tabular}{ccc}
\hline Variable & \multicolumn{2}{c}{ Neutrophil lymphocytic ratio } \\
\cline { 2 - 3 } Age & $\mathbf{r}$ & P-value \\
\hline NIHSS score on admission & 0.018 & 0.879 \\
NIHSS score after one month & 0.054 & 0.648 \\
mRS score on admission & 0.168 & 0.149 \\
mRS score after one month & 0.190 & 0.103 \\
\hline
\end{tabular}


All of the stroke subgroups patients had significantly higher neutrophils count compared to the controls $(\mathrm{P}<0.001)$. It seems that role of neutrophils, in particular, via secreting pro-inflammatory mediators such as proteolytic enzymes, arachidonic acid, elastase, and free oxygen radicals [12] is a constant role in ischemic stroke regardless its subtype. These neutrophil-mediated inflammatory processes cause additional tissue damage, plaque disruption, activation of coagulation pathways and thrombosis, microvascular plugging, myocyte necrosis and enlargement of the infarct size [13].

All of the stroke subgroups patients had significantly lower lymphocytes count compared to the controls $(\mathrm{P}<0.001)$. This may be due to that lymphocytes are more involved in regulation of immune responses. Reduced lymphocytes may be the result of an invasion of the edematous penumbra by immune cells and an associated decrease in serum lymphocytes associated with the infarct volume [14]. In contrast to neutrophils, lymphocytes infiltrating the ischemic area represent the regulatory arm of the inflammatory and cytotoxic response and play a significant role in the healing process of the ischemic area [13]. So, the inflammatory process occurring at the area of infarction is mediated by the complex interaction between innate neutrophil mediated reactive immune responses and subsequent lymphocyte mediated adaptive immune responses and this explains the increased NLR [15].

The above mentioned results of higher neutrophils and lower lymphocytes among patients with ischemic stroke compared to controls shall predict the finding that NLR was significantly higher among all of the stroke subgroups compared to the controls $(\mathrm{P}<0.001)$. Similar findings were reported in previous studies [6] [10] [16]. There were non-significant differences between the stroke subgroups when comparing the NLR to each other similarly to the finding in one study [17]. However another study [16] reported different results; it found that NLR levels were significantly higher in patients with large artery atherosclerosis when compared to other groups.

This study showed that NLR has a cutoff value more than 1.34 which had predicted AIS with a sensitivity of $89.33 \%$ and specificity of $72 \%$ and accuracy reached $88.6 \%$. The positive predictive value of NLR in stroke cases was $90.5 \%$ and the negative predictive value was $69.2 \%$.

This study revealed non-significant relationships between either severity or one-month outcome of ischemic stroke (assessed by NIHSS and mRS) and NLR. Although one study [4] found a significant correlation between severity of stroke and NLR, the absence of such correlation in this study can be attributed to one limitation of this study; the maximum NIHSS score of patient included in this study was 19, not including the patients with higher scores. This is attributed to the fact that the recruited patients were admitted to the stroke unit which is an intermediate care unit that is not equipped with mechanical ventilation that may be needed for patients with higher NIHSS scores. Additional large-scale studies are recommended to study the prognostic role of NLR in AIS. Also some studies [16] [17] reported a correlation between outcome of stroke and NLR. Yet it 
worth to mention that the latter studies were studying the mortality after ischemic stroke which was not the scope of this study that aimed studying the one month outcome after ischemic stroke.

\section{Conclusion}

NLR may be used as a simple, inexpensive and easy-to-use marker to predict sub-types of acute ischemic stroke (NLR was significantly higher in the large artery atherosclerosis stroke group then in the cardioembolic stroke group then in the lacunar stroke group). NLR > 1.34 is sensitive and reliable test to predict AIS. NLR is not a good predictor for short term (one month) outcome in AIS patients.

\section{Ethics}

The study was approved by the Ethics Board of Ain Shams University. All of the patients, or one of their first degree relatives if unable to understand or write, and controls participated in this study had signed an informed consent before enrollment in the study.

\section{Funding}

This research did not receive any specific grant from funding agencies in the public, commercial, or not-for-profit sectors.

\section{Conflicts of Interest}

The authors declare no conflicts of interest regarding the publication of this paper.

\section{References}

[1] Wang, X. (2014) Neutrophil to Lymphocyte Ratio in Relation to Risk of All-Cause Mortality and Cardiovascular Events among Patients Undergoing Angiography or Cardiac Revascularization: A Meta-Analysis of Observational Studies. Atherosclerosis, 234, 206-213. https://doi.org/10.1016/j.atherosclerosis.2014.03.003

[2] Papa, A., Emdin, M., Passino, C., et al. (2009) Predictive Value of Elevated Neutrophil-Lymphocyte Ratio on Cardiac Mortality in Patients with Stable Coronary Artery Disease. Clinica Chimica Acta, 395, 27-31. https://doi.org/10.1016/j.cca.2008.04.019

[3] Adams, H.P., Bendixen, B.H., Kappelle, L.J., et al. (1993) Classification of Subtype of Acute Ischemic Stroke. Definitions for Use in a Multicenter Clinical Trial. Stroke, 24, 35-41. https://doi.org/10.1161/01.STR.24.1.35

[4] Tokgoz, S., Kayrak, M., Akpinar, Z., et al. (2013) Neutrophil Lymphocyte Ratio as a Predictor of Stroke. Journal of Stroke \& Cerebrovascular Diseases, 22, 1169-1174. https://doi.org/10.1016/j.jstrokecerebrovasdis.2013.01.011

[5] Kumar, A.D., Boehme, A.K., Siegler, J.E., et al. (2013) Leukocytosis in Patients with Neurologic Deterioration after Acute Ischemic Stroke Is Associated with Poor Outcomes. Journal of Stroke \& Cerebrovascular Diseases, 22, 111-117. https://doi.org/10.1016/j.jstrokecerebrovasdis.2012.08.008 
[6] Saliba, W., Barnett-Griness, O., Elias, M., et al. (2015) Neutrophil to Lymphocyte Ratio and Risk of a First Episode of Stroke in Patients with Atrial Fibrillation: A Cohort Study. Journal of Thrombosis and Haemostasis, 13, 1971-1980. https://doi.org/10.1111/jth.13006

[7] Elkind, S. (2006) Inflammation, Atherosclerosis, and Stroke. The Neurologist, 12, 140-148. https://doi.org/10.1097/01.nrl.0000215789.70804.b0

[8] Megens, R.T., Vijayan, S., Lievens, D., et al. (2012) Presence of Luminal Neutrophil Extracellular Traps in Atherosclerosis. Trends in Immunology, 30, 538-546.

[9] Elkind, M.S.V., Sciacca, R.R., Boden-Albala, B., et al. (2005) Relative Elevation in Baseline Leukocyte Count Predicts First Cerebral Infarction. Neurology, 64, 21212125. https://doi.org/10.1212/01.WNL.0000165989.12122.49

[10] Guven, H., Çilliler, A.E., Sarikaya, S.A., et al. (2010) Erken Lökosit ve Nötrofil Yüksekliğinin Akut skemik nmede Etyolojik ve Prognostik Önemi. Journal of the Neurological Sciences ( Turk), 27, 311-318.

[11] Rodriguez-Yanez, M. and Castillo, J. (2008) Role of Inflammatory Markers in Brain Ischemia. Current Opinion in Neurology, 21, 353-357.

https://doi.org/10.1097/WCO.0b013e3282ffafbf

[12] Azab, B., Zaher, M., Weiserbs, K.F., et al. (2010) Usefulness of Neutrophil to Lymphocyte Ratio in Predicting Short- and Long-Term Mortality after Non-ST-Elevation Myocardial Infarction. American Journal of Cardiology, 106, 470-476. https://doi.org/10.1016/j.amjcard.2010.03.062

[13] Chavan, V., Patil, N. and Karnik, N.D. (2007) Study of Leukocytic Hydrolytic Enzymes in Patients with Acute Stage of Coronary Heart Disease. Indian Journal of Medical Sciences, 61, 73-82. https://doi.org/10.4103/0019-5359.30347

[14] Kraft, P., Drechsler, C., Schuhmann, M.K., et al. (2015) Characterization of Peripheral Immune Cell Subsets in Patients with Acute and Chronic Cerebrovascular Disease: A Case Control Study. International Journal of Molecular Sciences, 16, 25433-25449. https://doi.org/10.3390/ijms161025433

[15] Anzai, A., Anzai, T., Nagai, S., et al. (2012) Regulatory Role of Dendritic Cells in Post Infarction Healing and Left Ventricular Remodeling. Circulation, 125, 1234 1245. https://doi.org/10.1161/CIRCULATIONAHA.111.052126

[16] Gökhan, S., Ozhasenekler, A., Durgun, M.H., et al. (2013) Neutrophil Lymphocyte Ratios in Stroke Subtypes and Transient Ischemic Attack. European Review for Medical and Pharmacological Sciences, 17, 653-657.

[17] Ugur, L. and Umut, G. (2016) The Predictive Effect of the Neutrophil-to-Lymphocyte Ratio (NLR) on the Mortality of Acute Ischemic Stroke and Its Subtypes: A Retrospective Cross-Sectional Study. Eurasian Journal of Emergency Medicine, 15, 69-72. https://doi.org/10.5152/eajem.2016.39974 